\title{
Factors influencing on tourism sustainable development in Vietnam
}

\author{
Anh Vu Mai ${ }^{a *}$, Kim Chi Nguyen Thi ${ }^{b}$, Thanh Nga Nguyen Thi ${ }^{a}$ and Truong Le ${ }^{a}$
}

${ }^{a}$ Thanh Hoa University of Culture, Sports and Tourism, Vietnam

${ }^{b}$ Hanoi University of Business and Technology, Vietnam

CHRON I C L E

A B S T R A C T

Article history:

Received: November 27, 2019

Received in revised format: No-

vember 292019

Accepted: January 7, 2020

Available online:

January 8, 2020

Keywords:

Tourists

Sustainable tourism development

Social engagement

\begin{abstract}
The study aims to examine the factors affecting sustainable tourism development. First, the paper presents the literature review to show the related theories and overview of the tourism sector in Vietnam. Secondly, the research model and hypotheses are represented to test the relationships between influencing factors and sustainable tourism development. Finally, 329 questionnaires had been collected from state management agencies and tourism enterprises. By using SPSS and SmartPLS-SEM, the research shows that seven factors were affecting on sustainable tourism development in Vietnam. Specifically, social engagement has the strongest effect on sustainable tourism development, followed by state managerial competence respectively, tourism service quality, the quality of tourism human resource, infrastructure development, material tourism facilities and tourism resource.
\end{abstract}

\section{Introduction}

Tourism is seen as one of the world's largest economic sectors, which has already accounted for some essential steps in increasing the efficient utilization of energy and is increasingly implementing renewable energy technologies. These steps play important roles in creating jobs, leaving people out of poverty and protecting the environment. To keep pace with the rest of the world, it is the important for Vietnam to take essential initiatives which can accelerate in helping Vietnam become a sustainable tourism destination and hence, can ensure the long-term development of tourism sector. After 34 years of Renovation process (Đổi Mới Reform) since 1986, the economy of Vietnam has reached dramatic achievements, driving from a backward nation with more than 90 percent of the population working in agriculture field to become one of the most dynamic emerging economies in East Asia region. According to World Bank (2019), over 45 million Vietnamese people were lifted out of poverty and the poverty rates had decreased sharply from more than 70 percent to only below 6 percent in the period from 2002 to 2018. Moreover, gross domestic product (GDP) per capital has expanded by 2.5 times, accounting for 2,500 USD in 2018. After reaching a peak at 7.1 percent in 2018, real GDP growth continuously remained robust at $7.02 \%$ in 2019 . Thus, after three decades, Vietnam has had significant changes in many sectors such as agricultural production, industry and tourism field as well. Lam (2006) augured that Innovation Policy in 1986 had supported eco-tourism emerge becoming a new aspect for Vietnam in the tourism sector. Some researchers also believed that this system is open and dynamic (Butler, 1991; Mill \& Morrison, 1998; Tuan \& Rajargopal, 2019). The fact shows that tourists who came to Vietnam had increased in recent years and tourist attractions have been developed its business. Besides, the tourism industry has contributed significantly to GDP growth in Vietnam, Vietnamese people' awareness of ecotourism is still perceptible and ambiguous (Lam, 2006).

Some studies describe the impacts of tourism on the local citizen' perception towards tourism, especially in the developing nations (Pham, 2012). In recent years, Vietnam has taken account into economic development but neglected environmental 
problems. So, tourism development is seen as the key economics of Vietnam however, it is necessary to have sustainable solutions to develop sustainably (Pham \& Khin, 2015). As a result, the tourism sector is considered the general economic business that will only be developed by using tourism resources effectively. Thus, the great tourism resources, which include the natural vestiges, historic and multiple cultural landscapes, create unique attractions for tourists. Indeed, many factors including policy, society, culture, economy, environment, infrastructure, etc. have impacts on tourism sustainable development (Weichard, 1992; Mai, 2010). As a result, for developing tourism sustainably, it is necessary to have researches in terms of this field. There have been many studies on sustainable development of tourism, both in Vietnam and in the world. However, the factors influencing tourism sustainable development are based on different assumptions and different research sites. Thus, authors would like to develop the research model to investigate the factors affecting tourism sustainable development in the context transitional economy in Vietnam.

\section{Literature review and research model}

The overload exploitation and rapid development of tourism sectors have many influences on economic and social aspects, including environmental pollution and exhaustion of natural resources. Residents' awareness and their attitude towards tourism development are seen as the fundamental factor sustainable tourism development (Gursoy et al., 2009). Thus, the problems of sustainable tourism development in Vietnam play an important role in economic benefits, environmental protection and improving living standards. The constant development of the tourism sector had contributed to $13.9 \%$ GDP of Vietnam (25.5 billion USD), consisting of both direct and indirect contributions. This sector also creates more than 6,035 million jobs, the turnover of tourism industry accounted for more than 50\% among the exported services of the country (Nguyen, 2017). However, the tourism industry has to face many difficulties, in which some important targets have not been achieved, strategy to develop tourist market is not scientific, flexible to adapt to globalization context (Tuan \& Rajagopal, 2019).

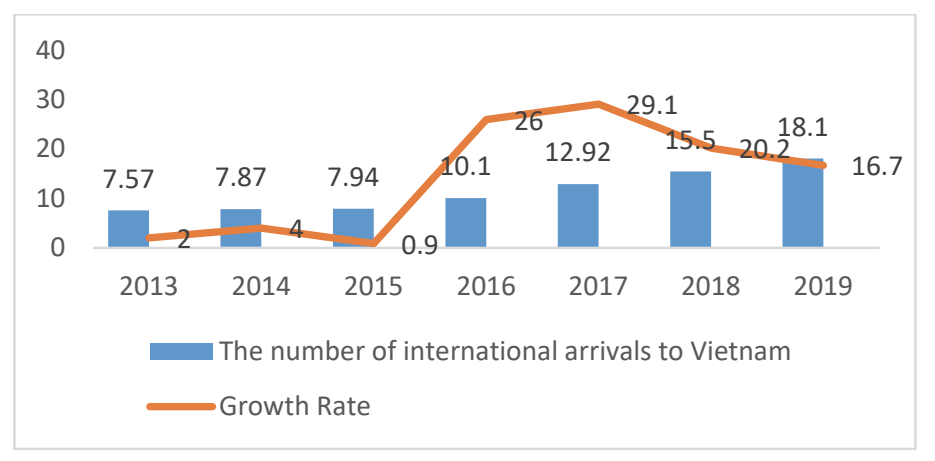

Fig. 1. Chart of international arrivals to Vietnam in the period of 2013-2019

According to the General Statistics Office of Vietnam (2019), the number of tourists coming to Vietnam reached 18.1 million people in 2019, increasing $16.7 \%$ compared with the year 2018. However, the growth rate of international tourists reduced from $20.2 \%$ (2018) to 18.1 (2019). This shows that after the period of strongest growth (2016-2017), this rate tended to decrease. Sustainable tourism is not just a temporary phenomenon; it has become the unavoidable tendency. The concept of "sustainable tourism" is proposed by World Conservation Union organization in 1996: "sustainable tourism is Environmentally responsible travel and visitation to natural areas, to enjoy and appreciate nature (and any accompanying cultural features, both past and present) in a way that promotes conservation, has a low visitor impact, and provides for beneficially active socio-economic involvement of local peoples". Hens (1998) states that sustainable tourism requires managing all resources in a way that we can meet economic, social and aesthetic needs while maintaining cultural identity, basis ecological processes, biodiversity and life assurance system. Machado (2003) argues that tourism forms may meet the current needs of tourists, the tourism industry and local communities, but it does not have effects on the abilities to meet the needs of future generations. Tourism is economically viable but does not destroy the resources in which the future of tourism depends on, especially the natural environment and social structure of the local community. Through the theoretical basis, authors synthesize the content of sustainable tourism development including 3 components: Economics, Culture-Society and Environment. There have many studies on sustainable tourism development. Jahan and Rahman (2016) have discovered that the main factors affecting sustainable tourism in Bangladesh include: Purchase incentives; Support services; Quality of service; Impacts of sustainable tourism; Participation of local people and related agencies; Level of responsibility; Natural resources and environment; Knowledge and caution of tourists. However, Tuan and Rajagopal (2019) identify the scale of factors and constructs the observed variables for each factor: Economic factors; Social factors; Environmental factors; Element of sustainable tourism development. Casey et al. (2004) believe that factors affecting tourism development in Australia include: Community; Land and cultural heritage management; Enterprises; Tourists. Based on the theories of sustainable development and literature review, the research model is proposed to test the proposed hypotheses. First, the infrastructure system brings the opportunity to develop tourism in remote areas; it also reduces overcome the seasonality in tourism and redistributes income to local residents. These are important bases for sustainable development in tourism. On the other hand, the development of tourism also requires the completion of infrastructure required by sustainable development. The above analysis shows that the development of infrastructure and sustainable development has a close relationship, and the infrastructure system is always an 
important basis for the construction and implementation of sustainable development of the locality. Thus, the following hypothesis is proposed to test this relationship:

\section{H1. The development of infrastructure has a positive effect on sustainable tourism development in Vietnam.}

Secondly, material tourism facilities are seen as an important factor affecting the level of tourists' satisfaction because of its capacity and utility. Technical and material facilities for tourism includes equipment and other necessary facilities to welcome tourists, places, entertainment and recreation areas. Using technical facilities to exploit the values of tourism resources, create services and goods provided to tourists. Therefore, it can be said that the level of development of tourism facilities and techniques is a necessary condition and is also the level of tourism development of a locality or a country.

\section{H2. Material tourism facilities have a positive effect on sustainable tourism development in Vietnam.}

Thirdly, tourism resources are natural landscapes, historical relics, revolutionary relics, human values, creative human works that can be used to satisfy tourism needs; it is also a basic factor to form tourist spots and resorts to create tourist attractions. Tourism resources include two groups: humanistic tourism resources and natural tourism resources. Natural tourism resources such as soil, water, climate, creatures, minerals, etc. form landscapes and terrain types, playing an important role in the process of attracting tourists and helping tourism. develop. Humanistic resources include the system of historical relics, cultural relics, customs, festivals, etc. which are the basic factors for tourism development. Natural resources are the basic factor to create tourism products, tourism sectors develop sustainably or not depends largely on this factor. The larger the scale of tourism resources, the higher their quality, the more likely they are to become an attractive destination for tourists, expanding and developing the tourism market.

\section{H3. Tourism resources have a positive effect on sustainable tourism development in Vietnam.}

Besides, the quality of tourism human resources is an important factor in the development of tourism. The quality of the business is greatly influenced by the use of quality labor because the workers working in the tourism sector not only carry out their tourism expertise but also perform their duties. It is important to exchange culture, communicate with visitors to make visitors feel excited while travelling. The more society develops, the greater the specialization for each profession, which requires workers to have in-depth skills for each field. The tourism industry needs deep expertise in their fields, which contributes to sustainable development not only for tourism but also for many other industries.

\section{H4. The quality of tourism human resource has a positive effect on sustainable tourism development in Vietnam.}

State managerial capacities are considered a factor affecting sustainable tourism development. A certain policy can inhibit or promote tourism development. State capacity to manage what extent will have an impact on sustainable tourism development corresponding to that extent.

\section{H5. State managerial capacities resource has a positive effect on sustainable tourism development in Vietnam.}

The quality of tourism services is one of the important factors to help tourism develop sustainably, which is a key factor to create a reputation and brand not only for tourism service providers but also for the tourism sector of the country. Standardizing travel services and improving service quality not only helps enterprises to ensure service quality, but it also contributes to increasing the length of stay, visiting spending, increasing foreign currency revenue from tourism.

\section{H6. Tourism service quality has a positive effect on sustainable tourism development in Vietnam.}

Finally, the involvement of the community in tourism activities makes the tourism sector more sustainable. Social engagement not only generates income for the community but also increases the responsibility for tourism development. This participation is essential and indispensable. If the awareness of the community on sustainable tourism is high, the development and implementation of the strategy of sustainable tourism development will be favorable, it will be difficult for the locality in the field of tourism development if their awareness is low.

H7. Social engagement has a positive effect on sustainable tourism development in Vietnam.

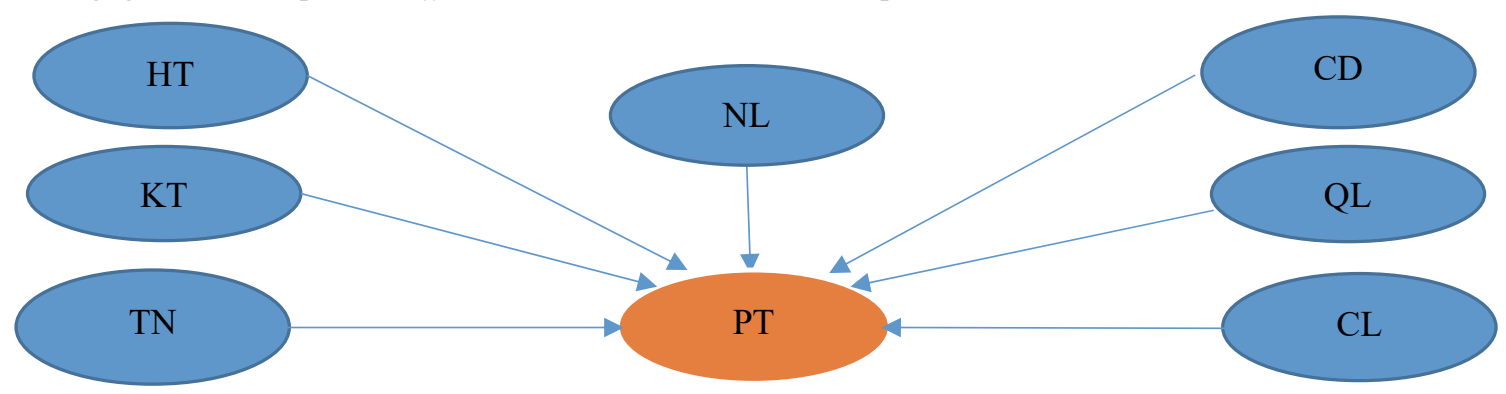

Fig. 2. Research Framework

HT: The development of infrastructure; KT: Material tourism facilities; TN: Tourism resources; NL: The quality of tourism human resource; CD: Social engagement; QL: State managerial capacities; CL: Tourism service quality; PT: Sustainable tourism development. 


\section{Methodology}

To achieve the research purpose, 365 questionnaires was distributed to state management agencies and tourism enterprises in Vietnam. However, only 352 questionnaires were sent back to authors while 23 questionnaires were not fulfil. Thus, there were just 329 fully answered questionnaires, which are used to analyse. The surveyed subjects include state management agencies and tourism enterprises. 114 questionnaires that were fulfilled by state management agencies accounted for $34.65 \%$ whereas 215 questionnaires were answered by tourism enterprises (65.35\%). After collecting data, the SPSS 20.0 and Smart PLS-SEM 3.2.7 are used to analyse the relationship between influencing factors and sustainable tourism development. Specifically, Cronbach's Alpha is used to assess the reliability of variables; Variance Inflation Factor (VIF) is implemented to test the possibility of multi-collinearity; Heterotrait-Monotrait Ratio (HTMT) is employed to examine the discriminant validity of scales; SEM (Structural equation modelling) is used to test the links between variables in the research model.

\section{Research results}

\subsection{The reliability of scales}

Since the indicators of the scales are adjusted but not completely inherited from previous studies, the EFA analysis procedure was applied to ensure the distinctiveness of the factor groups. The results of assessing reliability are showed in Table 1, which indicates that the scales ensure the distinction with the load factors of the indicators ensuring the actual meaning is greater than or equal to 0.5; Cronbach's Alpha guarantees greater than 0.6; KMO (Kaiser Meyer Olkin) is greater than 0.5; the total variance is greater than $50 \%$ (Hair et al., 2013). In addition, the research had removed the scale, which has a coefficient of less than 0.4 in order to help improve reliability (Hair et al., 2016).

Table 1

The results of assessing the reliability of scales by Cronbach's Alpha

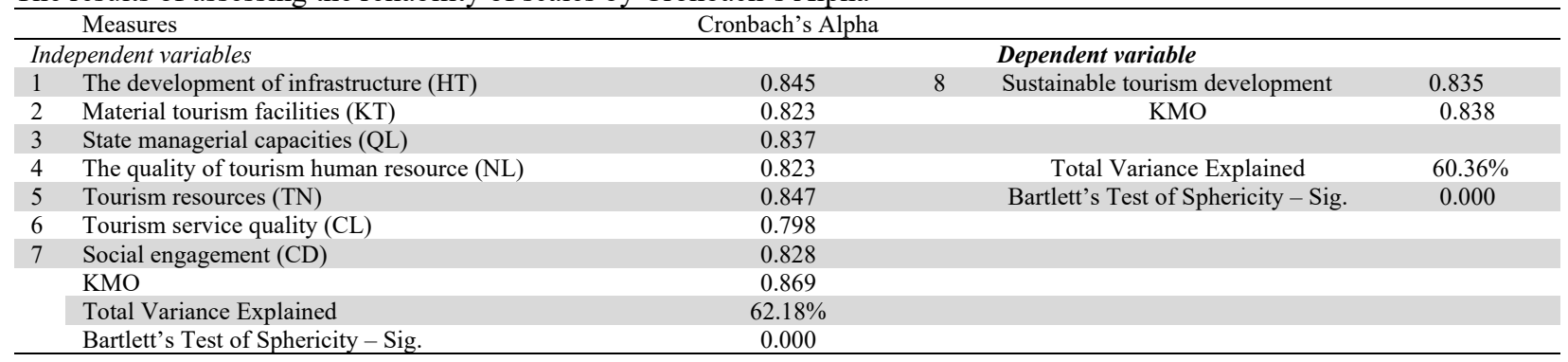

\subsection{The reliability of research model}

The reliability of the research model is considered carefully before testing the influence level of factors on sustainable tourism development.

Table 2

The reliability of the research model

\begin{tabular}{|c|c|c|c|c|c|}
\hline & Cronbach's Alpha & Rho_A & $\begin{array}{l}\text { Composite Reli- } \\
\text { ability }\end{array}$ & $\begin{array}{l}\text { Average Variance Ex- } \\
\text { tracted (AVE) }\end{array}$ & VIF \\
\hline Sustainable tourism development (PT) & 0.835 & 0.837 & 0.884 & 0.603 & \\
\hline Tourism service quality (CL) & 0.798 & 0.799 & 0.861 & 0.554 & 1.031 \\
\hline Material tourism facilities (KT) & 0.823 & 0.826 & 0.876 & 0.586 & 1.202 \\
\hline The development of infrastructure (HT) & 0.845 & 0.847 & 0.896 & 0.682 & 1.654 \\
\hline The quality of tourism human resource (NL) & 0.823 & 0.824 & 0.876 & 0.587 & 1.267 \\
\hline Social engagement (CD) & 0.828 & 0.828 & 0.886 & 0.660 & 1.688 \\
\hline State managerial capacities (QL) & 0.837 & 0.839 & 0.884 & 0.605 & 1.680 \\
\hline Tourism resources $(\mathrm{TN})$ & 0.847 & 0.848 & 0.891 & 0.620 & 1.292 \\
\hline
\end{tabular}

Table 2 presents the reliability of the research model, which includes some indicators: Cronbach's Alpha, Average Variance Extracted and composite reliability. Henseler et al. (2012) state that Cronbach's Alpha and Composite Reliability should be higher than 0.7 while AVE (Average Varian Extracted) must be not over 5 (Höck \& Ringle, 2006). Thus, the data of the research shows the necessary reliability. Moreover, the index of VIF (Variance Inflation Factor) shows the possibility of multi-collinear cases in the model. Hair et al. (2011) believe that VIF $<10$ is acceptable. However, to ensure the reliability, VIF index should not be greater than 5. R-Square Adjusted $=0.527$ is also appropriate for the study purpose. Discriminant validity of the model is ensured by the HTMT index which is the average of all correlations of items of each variable. HTMT index greater than 0.9 indicates that the two variables in the research lacked discriminant values, the acceptance threshold must be lower than 0.85 . Table 3 shows that the index has no value greater than 0.9 . 
Table 3

The results of analyzing the discriminant validity (HTMT-Heterotrait Monotraite Ratio)

\begin{tabular}{|c|c|c|c|c|c|c|c|c|}
\hline & $\mathrm{CL}$ & PT & KT & HT & NL & $\mathrm{CD}$ & QL & $\mathrm{TN}$ \\
\hline \multicolumn{9}{|l|}{ Tourism service quality (CL) } \\
\hline Sustainable tourism development (PT) & 0.233 & & & & & & & \\
\hline Material tourism facilities (KT) & 0.103 & 0.481 & & & & & & \\
\hline The development of infrastructure (HT) & 0.058 & 0.572 & 0.304 & & & & & \\
\hline The quality of tourism human resource (NL) & 0.110 & 0.538 & 0.277 & 0.289 & & & & \\
\hline Social engagement (CD) & 0.119 & 0.629 & 0.378 & 0.662 & 0.343 & & & \\
\hline State managerial capacities (QL) & 0.087 & 0.538 & 0.320 & 0.269 & 0.471 & 0.352 & & \\
\hline Tourism resources $(\mathrm{TN})$ & 0.078 & 0.611 & 0.404 & 0.633 & 0.364 & 0.605 & 0.395 & \\
\hline
\end{tabular}

\subsection{Structural and meta-analytic path analyses}

Table 4

The correlation between influencing factors and sustainable tourism development

\begin{tabular}{|c|c|c|c|c|c|}
\hline & $\begin{array}{l}\text { Original Sample } \\
\text { (O) }\end{array}$ & $\begin{array}{c}\text { Sample } \\
\text { Mean (M) }\end{array}$ & $\begin{array}{c}\text { Standard De- } \\
\text { viation } \\
(\mathrm{STDEV}) \\
\end{array}$ & $\begin{array}{l}\text { T Statistics } \\
(|\mathrm{O} / \mathrm{STDEV}|)\end{array}$ & P Values \\
\hline Tourism service quality $\rightarrow$ Sustainable tourism development & 0.182 & 0.186 & 0.036 & 5.060 & 0.000 \\
\hline Material tourism facilities $\rightarrow$ Sustainable tourism development & 0.141 & 0.141 & 0.041 & 3.441 & 0.001 \\
\hline The development of infrastructure $\rightarrow$ Sustainable tourism development & 0.157 & 0.158 & 0.049 & 3.187 & 0.002 \\
\hline The quality of tourism human resource $\rightarrow$ Sustainable tourism development & 0.182 & 0.182 & 0.039 & 4.653 & 0.000 \\
\hline Social engagement $\rightarrow$ Sustainable tourism development & 0.231 & 0.230 & 0.050 & 4.652 & 0.000 \\
\hline State managerial capacities $\rightarrow$ Sustainable tourism development & 0.193 & 0.192 & 0.039 & 5.008 & 0.000 \\
\hline Tourism resources $\rightarrow$ Sustainable tourism development & 0.137 & 0.138 & 0.049 & 2.791 & 0.005 \\
\hline
\end{tabular}

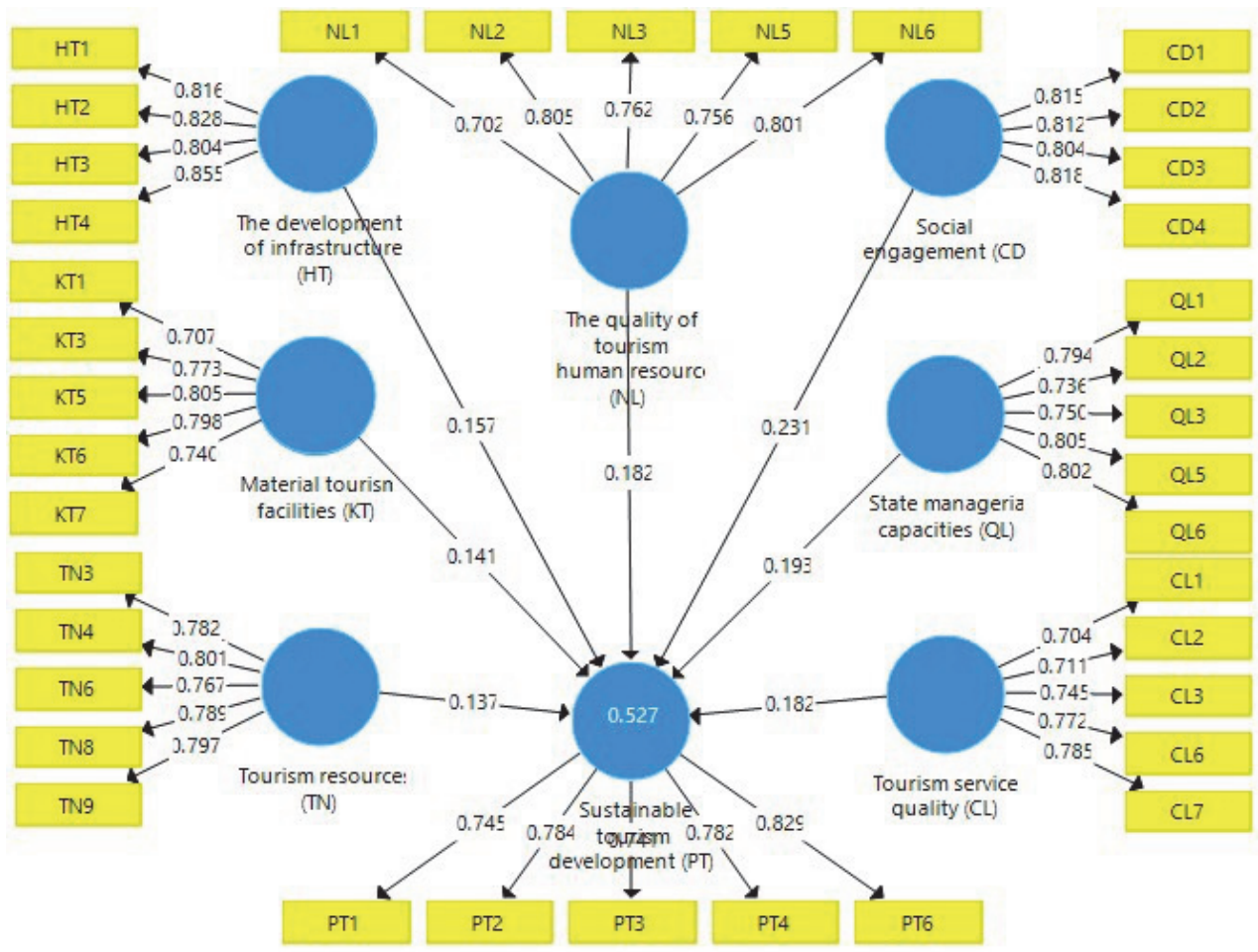

Fig. 3. The results of structural and meta-analytic path analyses

Table 5

Standardized Root Mean Square Residual (SRMR)

\begin{tabular}{lcc}
\hline & Saturated Model & Estimated Model \\
\hline SRMR & 0.051 & 0.051 \\
\hline
\end{tabular}

Table 4 shows that P-value of all relationships are lower than 0.05 whereas the table 5 indicates that Standardized Root Mean Square Residual (SRMR) is suitable for the research model. Hu and Bentler (1998) argue that SRMR should be lower than 0.08. Thus, hypotheses H1, H2, H3, H4, H5, H6, H7 are supported. The standardized regression equation is represented as PT $=0.231 * \mathrm{CD}+0.193 * \mathrm{QL}+0.182 * \mathrm{CL}+0.182 * \mathrm{NNL}+0.157 * \mathrm{HT}+0.141 * \mathrm{KT}+0.137 * \mathrm{TN}$ 


\section{Conclusion}

With 329 questionnaires evaluated by the state management agencies and tourism business units, the research results have shown that the sustainable tourism development in Vietnam is influenced by factors including: (1) tourism service quality; (2) material tourism facilities; (3) the development of infrastructure; (4) the quality of tourism human resource; (5) social engagement; (6) state managerial capacities and (7) tourism resources. This study is an important finding that social engagement had the strongest impact on sustainable tourism development in Vietnam, followed by tourism resources, the quality of tourism human resources, tourism service quality, material tourism facilities, the development of infrastructure and state managerial capacities. By using PLS - SEM, the research results have confirmed the rationality of PLS - SEM analysis method, especially in experimental research, which requires a close link from a theory to a linear structural model. Recently, Rasoolimanesh and Ali (2018) showed that the number of PLS-SEM applications in research has increased significantly in the past few years, but PLS-SEM is still new to many researchers.

\section{References}

Butler, R. W. (1991). Tourism, environment, and sustainable development. Environmental Conservation, 18(3), 201-209.

Casey, J. F., Brown, C., \& Schuhmann, P. (2010). Are tourists willing to pay additional fees to protect corals in Mexico?. Journal of Sustainable Tourism, 18(4), 557-573.

Gursoy, D., Chi, C. G., \& Dyer, P. (2009). An examination of locals attitudes. Annals of Tourism Research, 36(4), 723-726.

Hens, L. (1998). Tourism and Environment, M.Sc. Course, Free University of Brussel, Belgium

Henseler, J., Ringle, C. M., \& Sarstedt, M. (2012). Using partial least squares path modeling in advertising research: basic concepts and recent issues. Handbook of research on international advertising, 252.

Hock, M., \& Ringle, C. M. (2010). Local strategic networks in the software industry: an empirical analysis of the value continuum. International Journal of Knowledge Management Studies, 4(2), 132.

Jahan, N., \& Rahman, S. (2016, May). Identifying the key factors influencing sustainable tourism in Bangladesh: A Quantitative Analysis. In Asia Tourism Forum 2016-the 12th Biennial Conference of Hospitality and Tourism Industry in Asia. Atlantis Press.

Lam, T. D. (2004, June). Strategic planning and standards for ecotourism development in Vietnam. In Conference proceedings, The Sixth Asian Development Research Forum (ADRF) General Meeting (pp. 7-8).

Machado, A. (2003). Tourism and Sustainable Development, Capacity Building for Tourism Development in VietNam.

Mai. V. T, (2010). Systems thinking approach as a unique tool for sustainable tourism development: a case study in the cat ba biosphere reserve of Vietnam. Proceedings of the 54th Annual Meeting of the ISSS, Waterloo, Canada. Pp 1-19.

Mill, R. C., \& Morrison, A. M. (1998). The Tourism System: An Introductory Text (the 3rd Edition).

Nguyen. T. T. H, (2017). Current situation and solutions to promote the growth of Vietnam's tourism industry. Journal of Commerce. http://www.tapchicongthuong.vn/thuc-trangva-giai-phap-phat-trien-nganh-dulich-viet-nam-hien-nay-20170530111426127p0c488.htm. Retrieved on December, 2019

Pham, L. (2012). Tourism impacts and support for tourism development in Ha Long Bay, Vietnam: An examination of residents' perceptions. Asia Social Science, 8(8), 28-39

Pham. H. H., \& Khin. A. A. (2015). Sustainable competitive advantages for eco-tourism development of $\mathrm{Phu}$ Quoc Island: Background and literature reviews. Proceedings of the Second Asia-Pacific Conference on Global Business, Economics, Finance and Social Sciences (AP15Vietnam Conference). Pp1-7.

Rasoolimanesh, S. M., \& Ali, F. (2018). Partial least squares-structural equation modeling in hospitality and tourism. Journal of Hospitality and Tourism Technology, 9(3), 238-248.

Tuan, V. K., \& Rajagopal, P. (2019). Analyzing factors affecting tourism sustainable development towards vietnam in the new era. European Journal of Business and Innovation Research, 7(1), 30-42.

Weichard, R. S. (1992). Travel marketing: an introduction. McGraw-Hill

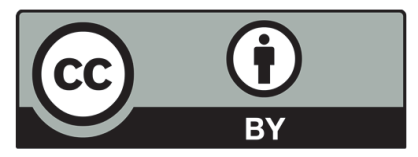

(C) 2020 by the authors; licensee Growing Science, Canada. This is an open access article distributed under the terms and conditions of the Creative Commons Attribution (CC-BY) license (http://creativecommons.org/licenses/by/4.0/). 